\title{
The Effect of Ultrasound Guided Rectus Sheath Block Versus Transversus Abdominis Plane Block for Pain Relief after Total Abdominal Hysterectomy
}

\author{
MOSTAFA M. ELBAGOURY, M.Sc.; MOHAMMAD I. OKAB, M.D.; SABRY M. AMIN, M.D. and \\ HESHAM I. ELTATAWY, M.D.
}

The Department of Anesthesia, Surgical Intensive Care and Pain Management, Faculty of Medicine, Tanta University

\begin{abstract}
Background: Total abdominal hysterectomy (TAH) is associated with substantial postoperative pain and discomfort. Transversus abdominis plane (TAP) block and rectus sheath (RS) block are used to block the sensory nerves of the anterior abdominal wall and thereby contributing in pain relief after lower abdominal surgeries.
\end{abstract}

Aim of Study: The aim of this study is to evaluate the effect of postoperative bilateral US-guided RS block versus postoperative bilateral US-guided TAB on analgesic requirements and hemodynamic changes after TAH.

Patients and Methods: This prospective randomized study was carried out on 60 females, ASA I or II presented for elective TAH under general anesthesia (GA)and randomly classified into 2 equal groups (each of 30 patients); patients in group I received $\mathrm{RS}$ block with $40 \mathrm{ml}$ bupivacaine $0.25 \%$ ( $20 \mathrm{ml}$ each side) before the end of surgery and in group II, patients received TAP block with $40 \mathrm{ml}$ bupivacaine $0.25 \%$ (20 $\mathrm{ml}$ each side) before the end of surgery. HR and MABP were measured as baseline, after induction of GA, every 15 min till end of surgery, immediately after recovery, at $2 \mathrm{~h}, 4 \mathrm{~h}$, $6 \mathrm{~h}, 8 \mathrm{~h}$ and $12 \mathrm{~h}$ postoperatively. Operative time, the duration of anesthesia and Numeric Rating Scale (NRS) at 2h, $4 \mathrm{~h}, 6 \mathrm{~h}$, $8 \mathrm{~h}$, and $12 \mathrm{~h}$ after recovery. Time to first analgesic request, total $24 \mathrm{~h}$ pethidine consumption and side-effects were measured.

Results: HR, MABP, and NRS score showed significant elevation at $6 \mathrm{H}$ and $8 \mathrm{H}$ postoperatively in group I. First time of analgesic request in group II was prolonged than group I. Pethidine consumption was reduced in group II compared to group I. Postoperative nausea and vomiting (PONV) showed elevation in group I compared to group II.

Conclusion: Postoperative bilateral US-guided TAB block was more effective than US-guided RS block in patients undergoing TAH with prolonged postoperative analgesia, less pethidine consumption, and less PONV.

Key Words: Transversus Abdominis Plane Block-Rectus Sheath Block - Total Abdominal Hysterectomy.

Correspondence to: Dr. Mostafa M. Elbagoury,

The Department of Anesthesia, Surgical Intensive Care and Pain Management, Faculty of Medicine, Tanta University

\section{Introduction}

TOTAL abdominal hysterectomy (TAH) is a commonly performed major surgical procedure that results in substantial postoperative pain and discomfort. Postoperative pain, if not treated promptly, can impair the patient's ability to ambulate which may lead to adverse effects such as thromboembolism, myocardial ischemia, arrhythmia. These patients require a multimodal postoperative pain treatment regimen that provides high-quality analgesia with minimal side effects [1-3]

Intravenous (IV) opioids remain the mainstay of analgesic regimen for patients post TAH. However, the use of opioids can result in significant side effects including sedation, nausea and vomiting. Therefore, alternative approaches, which reduce the requirement for strong opioids postoperatively are required $[2,3]$.

An important component of the pain experienced by patients after abdominal surgery derives from the abdominal wall incision. The abdominal wall sensory afferents course through the transverses abdominis (neurofascial) plane superficial to the transverses abdominis muscle then pierce posterior rectus sheath and course between the rectus muscle and its sheath [4]

Transversus abdominis plane (TAP) block and rectus sheath (RS) block are used to block the sensory nerves of the anterior abdominal wall and thereby contributing in pain reliefafterlower abdominal surgeries [ $\mathbf{s}$.

The aim of this study is to evaluate the effect of postoperative bilateral US-guided RS block versus postoperative bilateral US-guided $\mathrm{TAB}$ on 
analgesic requirements and hemodynamic changes after TAH.

\section{Patients and Methods}

This prospective randomized was carried out in Tanta University Hospitals on 60 females, American Society of Anesthiologist (ASA) physical status I or II scheduled for elective TAH from December 2017 to November 2018. A written informed consent was obtained from the patients. Every patient received explanation to the purpose of the study and had a secret code number to ensure privacy to participants and confidentiality of data. Research results were used for scientific purposes only, Procedures was approved by both the institutional and the regional ethical committees. Any unpredicted risks appeared duringthe research was clarifiedto the participants and to the ethical committee on time and proper measures were taken to overcome or minimize these risks.

Exclusion criteria were patient refusal, hepatic, renal or cardiac disease, any known allergy to local anesthetic, physical or mental conditions which may vague measuring postoperative pain following surgery, history of chronic use of analgesic as NSAIDs or CNS depressants as antiepileptic, and bleeding disorders.

Sixty patients were randomized using sealed numbered envelopes to one of two groups (30 patients each); group I received bilateral US-guided RS block at the end of surgery and group II: Received bilateral US guided TAP block at the end of surgery.

Medical \& surgical histories of patients were evaluated, clinical examination was performed, and all routine laboratory investigations were made. All patients received $150 \mathrm{mg}$ ranitidine and $10 \mathrm{mg}$ of metoclopramide one hour before anesthesia.

Routine monitoring of heart rate (HR) and rhythm by ECG, mean arterial blood pressure (MABP) using noninvasive blood pressure (NIBP), peripheraloxygen saturation ( $\mathrm{SpO} 2$ ) by using pulse oximeter were performed, an IV line was established with a $22 \mathrm{G}$ cannula.

All patients received a standardized general anesthetic technique for induction with $2 \mathrm{mcg} / \mathrm{kg}$ fentanyl, $2 \mathrm{mg} / \mathrm{kg}$ propofol, $0.15 \mathrm{mg} / \mathrm{kg}$ cisatracurium was given. Endotracheal tube with a propriate size was inserted after three minutes and confirmed by bilateral chest auscultation and capnography.
Anesthesia was maintained by $50 \%$ oxygen, $50 \%$ air and $1-1.5 \%$ Isoflurane. Intravenous fluid was maintained by $10 \mathrm{ml} / \mathrm{kg}$ ringer's lactate. Group 1 received, at the end of surgery and before extubation, US-guided bilateral RS block using 20-ml volume of bupivacaine $0.25 \%$ for each side, and group 2 received, at the end of the surgery and before extubation, US-guided bilateral TAB block using $20-\mathrm{ml}$ volume of bupivacaine $0.25 \%$ for each side. After completion of surgery, Inhalational anesthesia was stopped, and muscle relaxant was reversed with atropine and neostigmine and the patient allowed to breath spontaneously. The endotracheal tube was removed when the patients fulfilled the criteria of extubation (spontaneous eye opening, purposeful movement, intact reflexes) and the patients were transferred to post-anesthesia care unit (PACU) for further follow-up.

\section{Group I (US-guided RS block):}

After aseptic preparation of the injection sites, US transducer (linear 6-13MHz) (covered with sterile sheath) was placed in an axial (transverse) plane, above umbilicus, in the midline. Identify the rectus abdominis muscle as it's the only muscular layer in the midline. The peritoneal cavity lies deep to the posterior rectus sheath fascia and may be identified by the peristaltic movement of the bowel loops. A 22-gauge needle was inserted in-plane to the transducer in a medial to lateral direction with the end point in the fascial plane between the rectus muscle and posterior rectus sheath. The needle was connected to the syringe via extension tubing. Accurate placement of the needle tip was facilitated by injection of a small amount of fluid (1-2mL of saline or local anesthetic) to hydro dissect the appropriate plane. Correct needle tip position and deposition of local anesthetic was indicated by the appearance of a hypoechoic fluid pocket immediately deep to the hyperechoic fascial plane below the rectus abdominis muscle, and above the posterior rectus abdominis sheath. If the needle tip was intramuscular instead of in the correct plane, a pattern of fluid spread consistent with intramuscular fluid injection was seen instead. After negative aspiration, $20 \mathrm{~mL}$ of bupivacaine $0.25 \%$ was injected into this plane on each side. During local anesthetic injection, the abdomen was scanned cephalic and caudal to determine the extent of longitudinal spread. Medial and lateral scanning was determined the extent of horizontal spread.

\section{Group II (US-guided TAP block):}

After aseptic preparation of the injection sites, US transducer (linear 6-13MHz) (covered with 
sterile sheath) was placed in an axial (transverse) plane, above iliac crest, in the anterior axillary line. Identify the three muscular layers of the abdominal wall, the external oblique (most superficial), the internal oblique and transverses abdominis muscles. Among the three muscles, the internal oblique muscle is usually the most prominent layer. In the lower medial aspect of the abdominal wall, the external oblique muscle gives way tothe external oblique aponeurosis and may therefore appear as a layer of fascia instead of muscle. The peritoneal cavity lies deep to the transverses abdominis muscle and may be identified by the peristaltic movement of the bowel loops. A 22-gauge needle was inserted in-plane to the transducer in a medial to lateral direction with the end point in the fascial plane between the internal oblique muscle and transverses abdominis muscle. The needle was connected to the syringe via extension tubing. Accurate placement of the needle tip was facilitated by injection of a small amount of fluid (1-2mL of saline or local anesthetic) to hydro dissect the appropriate plane. Correct needle tip position and deposition of local anesthetic was indicated by the appearance of a hypoechoic fluid pocket immediately deep to the hyperechoic fascial plane between the internal oblique and transverses abdominis muscles. If the needle tip was intramuscular instead of in the correct plane, a pattern of fluid spread consistent with intramuscular fluid injection was seen instead. After negative aspiration, $20 \mathrm{~mL}$ of bupivacaine $0.25 \%$ was injected into this plane on each side. During local anesthetic injection, the abdomen was scanned cephalic and caudal to determine the extent of longitudinal spread. Medial and lateral scanning was determined the extent of horizontal spread.

\section{Measurements:}

Demographic data, HR and MABP were measured as baseline, after induction of general anesthesia, every $15 \mathrm{~min}$ till end of surgery, immediately after recovery, at $2 \mathrm{~h}, 4 \mathrm{~h}, 6 \mathrm{~h}, 8 \mathrm{~h}$ and $12 \mathrm{~h}$ postoperatively.

Operative time (from skin incision to skin closure) and the duration of anesthesia were measured. Postoperative Numeric Rating Scale (NRS) to assess pain intensity at $2 \mathrm{~h}, 4 \mathrm{~h}, 6 \mathrm{~h}, 8 \mathrm{~h}$, and $12 \mathrm{~h}$ after recovery (If NRS $>3$, pethidine $0.5 \mathrm{mg} / \mathrm{kg}$ was given IV and repeated every $3 \mathrm{~h}$ till the NRS less than 4 . Time to first analgesic request, total $24 \mathrm{~h}$ pethidine consumption and side-effects (such as nausea, vomiting, bradycardia and hypotension) were measured.
The primary outcome was the time to first analgesic request while the secondary outcomes werepain intensity by NRS, total amount of pethidine consumption and side effects.

\section{Statistical analysis:}

The sample size was calculated using the following assumption: The reduction in opioid consumption in the first $24 \mathrm{~h}$ postoperatively was the main response variable. Power analysis identifying 30 patients per group, required to detect $20 \%$ reduction in postoperative opioid consumption between both groups with a power $80 \%$ and a significant level of 0.05 .

The collected data were organized, tabulated and statistically analyzed using SPSSv25 (IBM, USA). For quantitative parametric data, mean and standard deviation were calculated and student ttest was used for comparison. For non-parametric data (NRS), median and range were calculated and Mann-Whitney U-test was used for comparison. For qualitative data, frequency and percentage were used and comparison was done using Chisquare test $\left(\mathrm{X}^{2}\right)$. The level of significance was adopted at $p$-value $<0.05$.

\section{Results}

In this study, 70 patients were assessed for eligibility; 5 patients did not meet the inclusion criteria and 5 patients refused to participate in the study. 60 patients were randomized into two groups 30 patients in each one; group I: RS block and group II: TAP block. All patients are followed-up and analyzed Fig. (1).

In our study, there was no significant difference between both groups as regard demographic data (age, weight, operative time and duration of anesthesia) Table (1). Comparison of the mean value of HR among the studied groups revealed that there was significant elevation at 6 hour and $8 \mathrm{H}$ postoperatively in group I compared to group II. Comparison of the mean value of MABP among the studied groups revealed that there was significant elevation at 6 hour and $8 \mathrm{H}$ postoperatively in group I compared to group II Figs. (2,3). NRS score was significant elevated at $6 \mathrm{H}$ and $8 \mathrm{H}$ postoperatively in group I compared to group II Table (2). First time of analgesic request in group II was prolonged in duration than group I. Pethidine consumption was reduced in group II compared to group I Table (1). As regard side effects: PONV was significantly increase in group I compared to group II Fig. (5). 


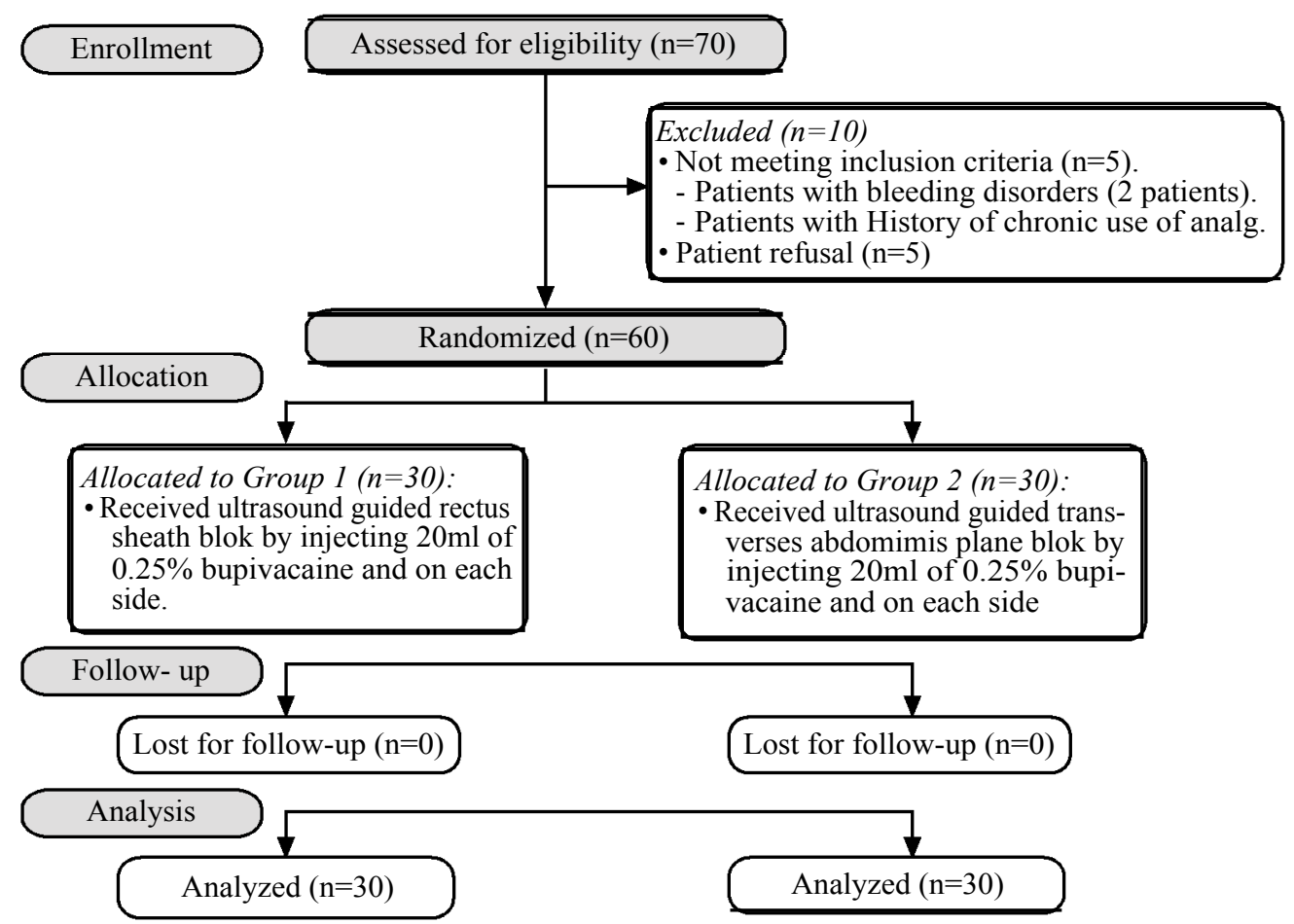

Fig. (1): Patient flowchart.

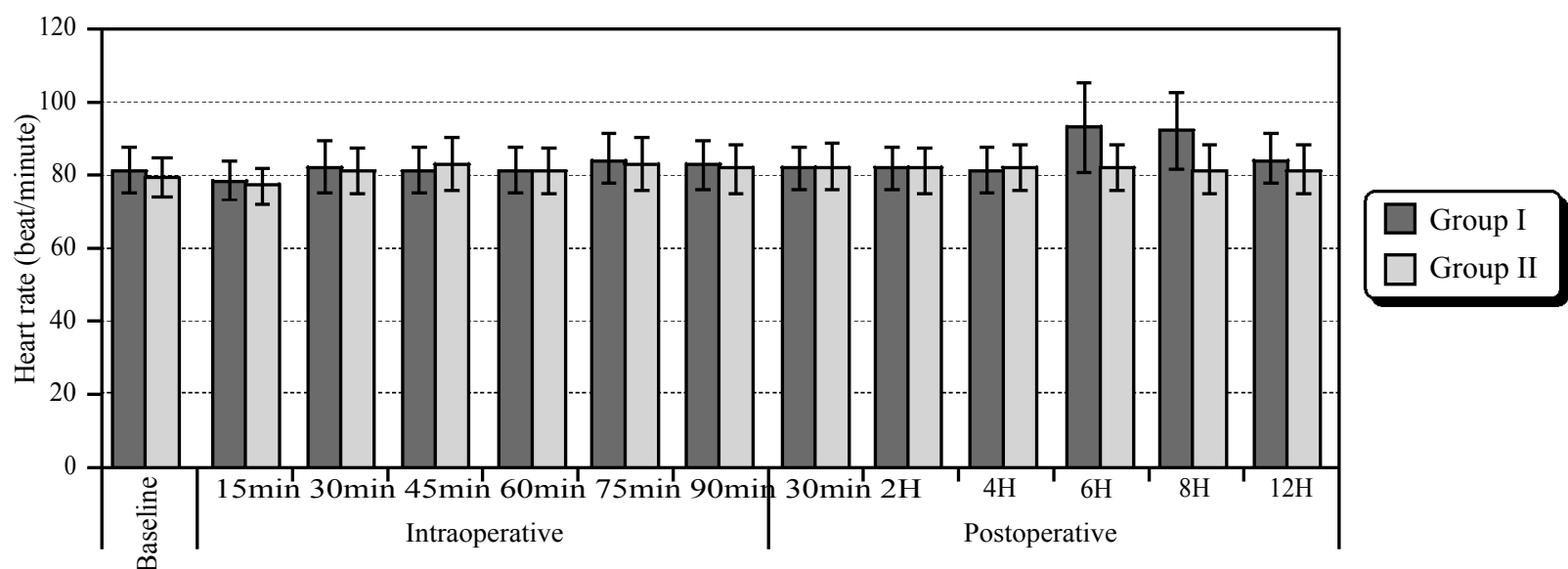

Fig. (2): Heart rate between the two groups.

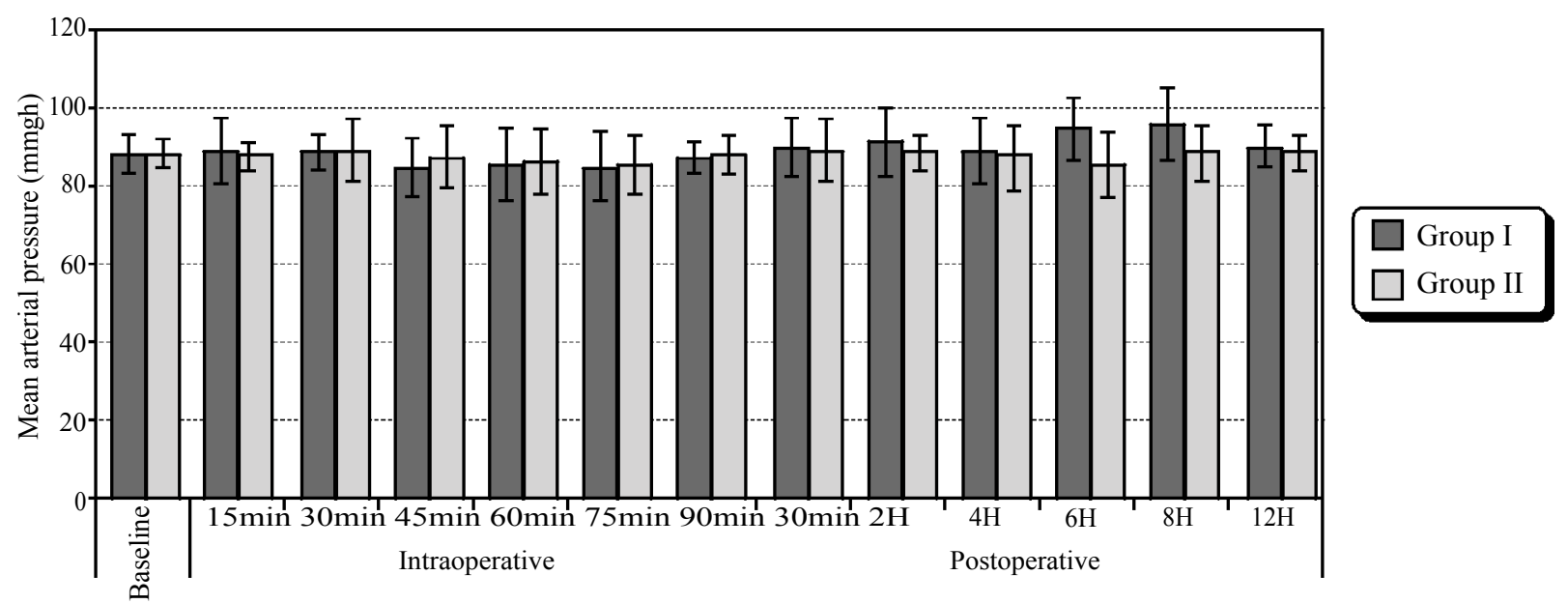

Fig. (3): Mean arterial blood pressure between the two groups. 


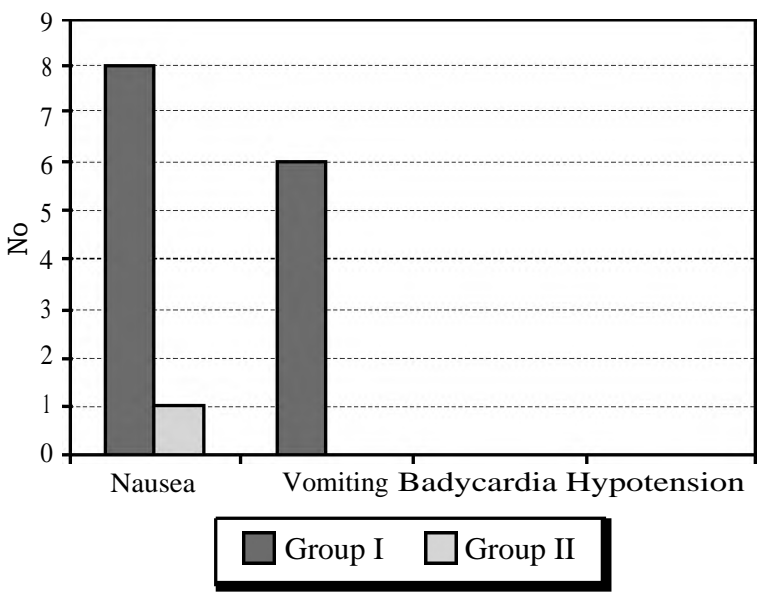

Fig. (4): Postoperative complications in both groups.

Table (1): Patients' demographic data, operative time, duration of anesthesia, time of first analgesic requirement and total pethidine consumption of the studied groups.

\begin{tabular}{llll}
\hline & \multicolumn{1}{c}{$\begin{array}{c}\text { Group I } \\
(\mathrm{n}=30)\end{array}$} & $\begin{array}{c}\text { Group II } \\
(\mathrm{n}=30)\end{array}$ & $\begin{array}{c}p \text { - } \\
\text { value }\end{array}$ \\
\hline Age (years) & $46.47 \pm 5.21$ & $46.67 \pm 4.6$ & 0.79 \\
$\begin{array}{l}\text { Weight (Kg) } \\
\begin{array}{l}\text { Operative time } \\
\text { (min) }\end{array}\end{array}$ & $83.2 \pm 6.09$ & $84 \pm 5.84$ & 0.53 \\
$\begin{array}{c}\text { Duration of } \\
\text { anesthesia (min) }\end{array}$ & $93.97 \pm 9.08$ & $94.07 \pm 8.45$ & 0.92 \\
$\begin{array}{c}\text { Time of first } \\
\text { analgesic } \\
\text { requirement (min) }\end{array}$ & $210.1 \pm 77.36$ & $334.5 \pm 75.34$ & $<0.001 *$ \\
$\begin{array}{c}\text { Total pethidine } \\
\text { consumption } \\
\text { (mg) }\end{array}$ & $194 \pm 48.26$ & $130.4 \pm 43.06$ & $<0.001 *$ \\
\hline
\end{tabular}

Table (2): Comparison of Numeric Rating Scale (NRS) in both groups.

\begin{tabular}{llllll}
\hline $\mathrm{N}$ & $2 \mathrm{H}$ & $4 \mathrm{H}$ & $6 \mathrm{H}$ & $8 \mathrm{H}$ & $12 \mathrm{H}$ \\
\hline $\begin{array}{c}\text { Group I: } \\
\text { Median }\end{array}$ & 3 & 3 & 4 & 4 & 3 \\
Range & $1-4$ & $1-4$ & $1-6$ & $1-6$ & $1-5$ \\
Group II: & & & & & \\
Median & 3 & 3 & 3 & 3 & 2 \\
Range & $1-4$ & $1-3$ & $1-4$ & $1-4$ & $1-4$ \\
-value & 0.35 & 0.67 & $<0.001 *$ & $<0.001 *$ & 0.44 \\
\hline
\end{tabular}

\section{Discussion}

The main cause of postoperative pain after abdominal surgeries is the abdominal wall incision. Injection of local anesthetics into the fascial planes will result in block the nerves of anterior abdominal wall before they pierce the musculature to innervate the abdomen wall [6].
The TAP block is a regional analgesic technique which blocks T6-L 1 nerve branches and has an evolving role in postoperative analgesia for lower abdominal surgeries [7].

A significant advantage of peripheral nerve block technique is early mobility. Excellent analgesia along with minimal motor block of the limbs and no mandatory connection to infusion devices allow early patient mobilization. This leads to major benefits including reduced potential for deep vein thrombosis and pulmonary embolus, lesser incidence of atelectasis and respiratory infection, and minimal motor deconditioning [8] .

The advantage of US for peripheral nerve block is the ability to confirm local anesthetic spread around the target nerve [9].

As regard to hemodynamic changes, the mean value of HR and MABP in group I showed significant elevation at $6 \mathrm{~h}$ and $8 \mathrm{~h}$ postoperatively compared to baseline mean value in the same group and in comparison, with the mean value of heart rate and mean arterial blood pressure at $6 \mathrm{~h}$ and $8 \mathrm{~h}$ postoperatively in group II.

These results demonstrated that, performing postoperative bilateral US-guided TAP block or bilateral US guided RS block was associated with stable hemodynamic but RS block group showed significant increase in heart rate and mean arterial blood pressure postoperatively in comparison to TAP block group. This could be explained by the elevation of pain score at $6 \mathrm{~h}$ and $8 \mathrm{~h}$ postoperatively in group I in comparison with group II.

These results were in line with Ripollés et al., who found that therewere no hemodynamic changes with TAP block in postoperative period and concluded that TAP block is an effective technique for reducing opioid use postoperatively following colorectal surgery, caesarean section, cholecystectomy, hysterectomy, appendectomy, retropubic prostatectomy, and bariatric surgery [10]

As regard to post-operative pain, comparison of the mean value of NRS score among the studied groups (primary outcome of the study) revealed that, there was significant increase in NRS score in group I at $6 \mathrm{~h}, 8 \mathrm{~h}$ postoperatively compared to group II. The mean value of first time of analgesic request was in group II was prolonged in duration than group I. The mean value of total pethidine consumption was significantly more in group I than group II. 
These results demonstrated that, the quality of postoperative analgesia was superior and more prolonged in duration in patients received USguided TAP block than patients received US-guided RS block.

This could be explained by rectus sheath block technique is used to block the terminal branches of the 9 th, 10th, and 11 th intercostal nerves which run in between the internal oblique and transverses abdominis muscles to penetrate the posterior wall of the rectus abdominis muscle and end in an anterior cutaneous branch supplying the overlying skin of the umbilical area. Local anesthetic deposition within the posterior rectus sheath bilaterally provides dense and predictable analgesia over the middle of anterior wall from the xiphoid process to the symphysis pubis; it is therefore used for surgery with midline (or paramedian) abdominal incision. RS block, compared to TAP block, is more effective in midline and paramedian abdominal incisions above the umbilicus than TAP block, which is mainly useful for transverse or pfennensteil incisions below the umbilicus. In TAP block, single injection is enough for several days while frequent dosage is required in case of bilateral RS block hence, insertion of rectus sheath catheters is essential [11].

These resultswere in line with Jadon et al., They proved that the median time to first analgesic request was prolonged in the TAP group compared to the control group $p<0.0001$. The median number of doses of tramadol consumed in the TAP group was significantly lower compared to the control group. At all points in the study, pain scores both at rest and on movement were lower in the study group. The study concluded that TAP block reduces pain, prolongs the duration of analgesia and decreases supplemental opioid consumption when used for multimodal analgesia for pain relief after caesarean section [12]

Additionally, Pratheeba et al., reported that the quality of analgesia along with lesser rescue analgesic requirement and their side effects makes the TAPB a good and safer option for lower abdominal gynecological surgeries [13].

Moreover, Karatepe et al., concluded that USguided TAPB performed after spinal anesthesia results in lower VAS scores and reduced analgesic consumption [14]

Also, Melnikov et al., Demonstrated that, the analgesic effectiveness of both paravertebral block (PVB) and TAP block after major gynecological cancer surgery. Both had significant reductions in both opioid requirements and pain scores during early and late postoperative periods [15].

Also, Amin et al., concluded that preoperative US-guided bilateral TAP block in patients undergoing colorectal surgery was associated with reduction in the analgesic requirements postoperatively [16]

Tan et al., concluded that, Patients in TAP block group consumed less morphine in 24 hours than those in the control group (12.3 vs $31.4 \mathrm{mg}$ ) [17] Shin et al., Proved that, US-guided TAP block provided more effective analgesia after gynecological surgery. His study was conducted on 32 patients randomized to undergo gynecological surgery with postoperative PCA or to receive US-TAP block. The VNRS pain score was significantly lower in the US- TAP group [18]. Hebbard et al., found that, incaesarean delivery parturient, TAP block was associated with reduction in the postoperative patient-controlled IV morphine requirement [19].

Also, Carney et al., reported that TAP block has been demonstrated to be effective in patients undergoing TAH, VAS pain score was lower in TAP block group in most time points assessed [20]

In controversy to this study Costello et al., concluded that, TAP block did not improve the quality of postoperative pain after caesarean section delivery [21].

Additionally, Ghisi et al., found that, TAP block did not reduce morphine consumption during the first postoperative $24 \mathrm{~h}$ after elective total hysterectomy [22].

These studies were not able to show any differences between postoperative analgesic requirement because TAP block was used as a multimodal analgesic regimen in patients who received spinal anesthesia which increases the duration of postoperative analgesia. In the present study, TAP block was used as a postoperative analgesic regimen in patients who received general anesthesia.

Moreover, Loane reported that, TAP block was associated with greater supplemental morphine requirements than intrathecal morphine in 24 hours when conducted on 66 women undergoing elective caesarean delivery under spinal anesthesia and randomized to receive either intrathecal morphine plus TAP or a TAP [23]

Also, McMorrow et al., compared the analgesic efficacy of the TAP block with and without spinal morphine after Caesarean section in a prospective, 
randomized, double-blinded placebo-controlled trial and concluded that, Spinal morphine but not TAP block improved analgesia after Caesarean section. The addition of TAP block with bupivacaine to spinal morphine did not further improve analgesia [24].

The disagreement most probably due to the use of morphine intrathecally which increases the duration of analgesia as intrathecal morphine is very potent with prolonged period of analgesia, but its usage accompanied by many side effects like itching, nausea, vomiting and respiratory depression.

As regard to side effects, there was significant increase in the incidence of PONV in group I compared to group II. There was no significant difference in other postoperative complications in the two groups. This could be explained by more postoperative pethidine that was used in patients received RS block than patients received TAP block.

These results were in line with Carney et al., They compared the analgesic efficacy of ipsilateral TAB block after appendectomy in children vs placebo and found that, there was no significant difference in the incidence of nausea or distribution of nausea scores between the two studied groups at any time interval [25].

Also, Baeriswyl et al., meta-analysis found that, Pain ratings were reduced at 6 hours postoperatively, but no effect was seen in the incidence of postoperative nausea and/or sedation, either at rest or during movement. The authors conclude that US-guided TAP block provides safe postoperative analgesic efficacy after abdominal laparotomy or laparoscopy and cesarean delivery [26]

Also, Johns et al., found that, TAP block was associated with lower incidence of postoperative nausea and vomiting [27] .

Also, Siddiqui et al., published a meta-analysis around the efficacy of the TAP block and found that, no significant effects from the TAP block were noticed in postoperative nausea and vomiting [28].

\section{Conclusion:}

Postoperative bilateral US-guided TAB block was more effective than US-guided RS block in patients undergoing TAH with prolongedpostoperative analgesia, less pethidine consumption and less postoperative nausea and vomiting.

\section{Conflicts of interest: Nil.}

Authors' Contributions: All authors had equal role.

\section{References}

1- STANLEY G., APPADU B., MEAD M. and ROWBOTHAM D.J.: Dose requirements, efficacy and side effects of morphine and pethidine delivered by patient-controlled analgesia after gynaecological surgery. Br. J. Anaesth., 76: 484-6, 1996.

2- NG A., SWAMI A., SMITH G., DAVIDSON A.C. and EMEMBOLU J.: The analgesic effects of intraperitoneal and incisional bupivacaine with epinephrine after total abdominal hysterectomy. Anesth. Analg., 95: 158-62, table of contents, 2002.

3- WOODHOUSE A. and MATHER L.E. : The effect of duration of dose delivery with patient-controlled analgesia on the incidence of nausea and vomiting after hysterectomy. Br. J. Clin. Pharmacol., 45: 57-62, 1998.

4- NETTER F.: Back and spinal cord. In: Netter F., editor. Atlas of human anatomy summit. $4^{\text {th }}$ ed. New Jersey, USA: The Ciba-Geigy Corporation, p. 145-55, 1989.

5- BELAVY D., COWLISHAW P.J., HOWES M. and PHILLIPS F.: Ultrasound-guided transversus abdominis plane block for analgesia after Caesarean delivery. Br. J. Anaesth., 103: 726-3 0, 2009.

6- EJLERSEN E., ANDERSEN H.B., ELIASEN K. and MOGENSEN T.: A comparison between preincisional and postincisional lidocaine infiltration and postoperative pain. Anesth. Analg., 74: 495-8, 1992.

7- PETERSEN P.L., MATHIESEN O., TORUP H. and DAHL J.B.: The transversus abdominis plane block: A valuable option for postoperative analgesia? A topical review. Acta. Anaesthesiol. Scand, 54: 529-35, 2010.

8- LISSAUER J., MANCUSO K., MERRITT C., PRABHAKAR A., KAYE A.D. and URMAN R.D.: Evolution of the transversus abdominis plane block and its role in postoperative analgesia. Best. Pract. Res. Clin. Anaesthesiol., 28: 117-26, 2014.

9- RETZL G., KAPRAL S., GREHER M. and MAURITZ W.: Ultrasonographic findings of the axillary part of the brachial plexus. Anesth. Analg., 92: 1271-5, 2001.

10- RIPOLLES J., MEZQUITA S.M., ABAD A. and CALVO J.: Analgesic efficacy of the ultrasound-guided blockade of the transversus abdominis plane-a systematic review. Braz. J. Anesthesiol., 65: 255-80, 2015.

11- O'DONNELL B.D., MCDONNELL J.G. and MCSHANE A.J.: The transversus abdominis plane (TAP) block in open retropubic prostatectomy. Reg. Anesth. Pain Med., 31: 91, 2006.

12- JADON A., JAIN P., CHAKRABORTY S., MOTAKA M., PARIDA S.S., SINHA N., et al.: Role of ultrasound guided transversus abdominis plane block as a component of multimodal analgesic regimen for lower segment caesarean section: A randomized double blind clinical study. BMC. Anesthesiol., 18: 53, 2018.

13- PRATHEEBA N., REMADEVI R., RAAJESH I.J., BHAVANI V., TRIPATHY D.K. and BHAT R.R.: Comparison 
of Postoperative Analgesic Efficacy of Wound Site Infiltration and Ultrasound-guided Transversus Abdominis Plane Block with 0.5\% Ropivacaine in Lower Abdominal Surgeries under Spinal Anesthesia. Anesth. Essays Res., 12: 80-4, 2018.

14- KARATEPE U. and OZER A.B.: Evaluation of postoperative analgesic efficacy of transversus abdominis plane block in patients who underwent caesarian section under spinal anesthesia. Biomed. Res., 29: 2101-5, 2019.

15- MELNIKOV A.L., BJOERGO S. and KONGSGAARD U.E.: Thoracic paravertebral block versus transversus abdominis plane block in major gynecological surgery: a prospective, randomized, controlled, observer-blinded study. Local. Reg. Anesth., 5: 55-61, 2012.

16- AMIN S.M. and MOHAMMAD R.M.: The Effect of a preoperative single dose of magnesium sulfate versus preoperative ultrasound guided bilateral transversus abdominis plane block on hemodynamics and postoperative analgesic requirements in patients undergoing colorectal surgery. J. Anesth. Clin. Res., 8: 2, 2017.

17- TAN T.T., TEOH W.H., WOO D.C., OCAMPO C.E., SHAH M.K. and SIA A.T.: A randomised trial of the analgesic efficacy of ultrasound-guided transversus abdominis plane block after caesarean delivery under general anaesthesia. Eur. J. Anaesthesiol., 29: 88-94, 2012.

18- SHIN H.J., KIM S.T., YIM K.H., LEE H.S., SIM J.H. and SHIN Y.D.: Preemptive analgesic efficacy of ultrasoundguided transversus abdominis plane block in patients undergoing gynecologic surgery via a transverse lower abdominal skin incision. Korean. J. Anesthesiol., 61: 4138, 2011.

19- HEBBARD P.D., BARRINGTON M.J. and VASEY C.: Ultrasound-guided continuous oblique subcostal transversus abdominis plane blockade: Description of anatomy and clinical technique. Reg. Anesth. Pain Med., 35: 43641, 2010.

20- CARNEY J., MCDONNELL J.G., OCHANA A., BHINDER R. and LAFFEY J.G.: The transversus abdominis plane block provides effective postoperative analgesia in patients undergoing total abdominal hysterectomy. Anesth. Analg., 107: 2056-60, 2008.
21- COSTELLO J.F., MOORE A.R., WIECZOREK P.M., MACARTHUR A.J., BALKI M. and CARVALHO J.C.: The transversus abdominis plane block, when used as part of a multimodal regimen inclusive of intrathecal morphine, does not improve analgesia after cesarean delivery. Reg. Anesth. Pain Med., 34: 586-9, 2009.

22- GHISI D., FANELLI A., VIANELLO F., GARDINI M., MENSI G., LA COLLA L., et al.: Transversus Abdominis Plane Block for Postoperative Analgesia in Patients Undergoing Total Laparoscopic Hysterectomy: A Randomized, Controlled, Observer-Blinded Trial. Anesth. Analg., 123: 488-92, 2016.

23- LOANE H., PRESTON R., DOUGLAS M.J., MASSEY S., PAPSDORF M. and TYLER J.: A randomized controlled trial comparing intrathecal morphine with transversus abdominis plane block for post-cesarean delivery analgesia. Int. J. Obstet. Anesth., 21: 112-8, 2012.

24- MCMORROW R.C., NI MHUIRCHEARTAIGH R.J., AHMED K.A., ASLANI A., NG S.C., CONRICKMARTIN I., et al.: Comparison of transversus abdominis plane block vs spinal morphine for pain relief after Caesarean section. Br. J. Anaesth., 106: 706-12, 2011.

25- CARNEY J., FINNERTY O., RAUF J., CURLEY G., MCDONNELL J.G. and LAFFEY J.G.: Ipsilateral transversus abdominis plane block provides effective analgesia after appendectomy in children: A randomized controlled trial. Anesth. Analg., 111: 998-1003, 2010.

26- BAERISWYL M., KIRKHAM K.R., KERN C. and ALBRECHT E.: The analgesic efficacy of ultrasound-guided transversus abdominis plane block in adult patients: A Meta-Analysis. Anesth. Analg., 121: 1640-54, 2015.

27- JOHNS N., O'NEILL S., VENTHAM N.T., BARRON F., BRADY R.R. and DANIEL T.: Clinical effectiveness of transversus abdominis plane (TAP) block in abdominal surgery: A systematic review and meta-analysis. Colorectlm. Dis., 14: e635-42, 2012.

28- SIDDIQUI M.R., SAJID M.S., UNCLES D.R., CHEEK L. and BAIG M.K.: A meta-analysis on the clinical effectiveness of transversus abdominis plane block. J. Clin. Anesth., 23: 7-14, 2011. 


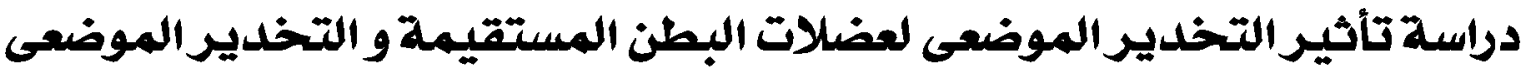

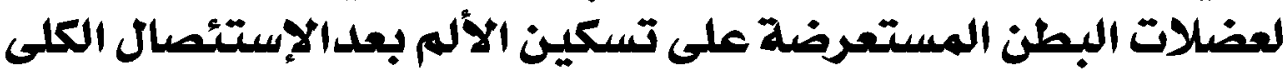 للرحم عن طريق البطن عنيكن}

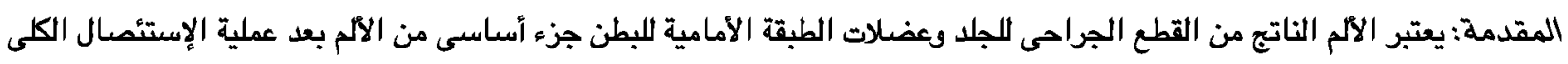
الرحم عن طريق البطن. يتطلب هؤلاء المرضى تداخل أكثر من طريقة لتسكين الألم المئ.

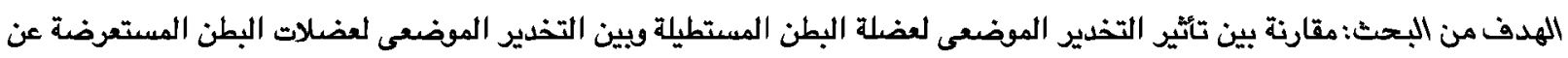

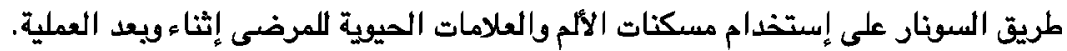

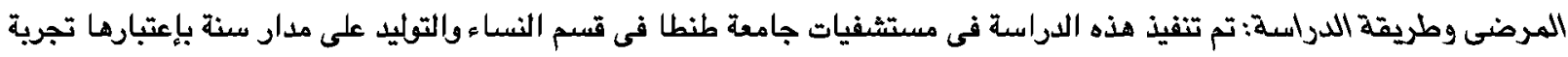

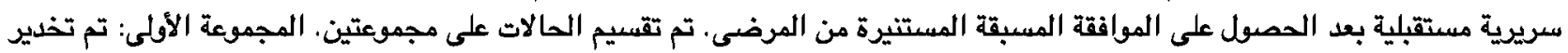
عضلة البطن المستقيمة والمجموعة الثانية: تم تخدير عضلة البطن المستعرضة بواسطة حقن البيوبيفاكين. معايير الأشتمال: المرضى الذين تتراوح أعمارهم بين (.ع-.V سنة) وتقييم الحالة الصحية لهم (1-r) حسب المنظومة الأمريكية التخدير. معايير الأستبعاد : المرضى الذين رفضوا هذه التقنيات والذين يعانون من فشل فى وظائف الكبد أو القلب أو يعانون من حساسية من المخدر الموضعى أو المرضى الذين يستخدمون مسكنات الألم بشكل مزمن.

القياسات: العلامات الميوية للمرضى أثثاء وبعد العملية ولرجة الألم بإستخدام معدل قياسات الألم وتوقيت طلب المريض للمسكن لأول

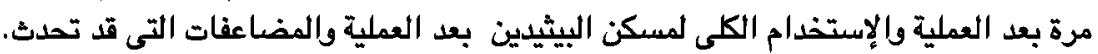

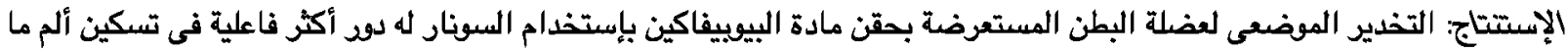
بعد عملية الإستئصال الكلى للرحم عن طريق البطن وأقل فى حدى الفثيان والقئ بعد العملية مقارنة بالتخدير الموضعى لعضلة البطن المستقيمة بحقن مادة البيوييفاكين بإستخدام السيونار. 